\title{
Effect of Mill Type on Morphology of AA6013 Aluminium Powder
}

\author{
${ }^{1}$ Department of Machine and Metal Technology, Akhisar Vocational School, Celal Bayar University, Akhisar/Manisa, \\ TURKEY. \\ e-mail: r.onur.uzun@cbu.edu.tr \\ ${ }^{2}$ Department of Materials Engineering, Faculty of Engineering, Celal Bayar University, Muradiye/Manisa, TURKEY. \\ e-mail: hulya.durmus@cbu.edu.tr
}

\begin{abstract}
In conventional recycling method, metal chips are cast after pressing and melting in electric arc furnace. Material loss occurs during the recycling from liquid metal due to the several reasons. Direct recycling method which produces the aluminium powder from aluminium chips using mechanical mill can be an alternative to conventional recycling method. Thus material and energy losses, and labour cost will be reduced by direct recycling method without melting.

In this study, the particle morphology of powder direct recycled from AA6013 aluminium alloy chips with cryogenic, disc and ball type grinders is investigated. Mechanical milling resulted flaky and irregular shaped AA6013 particles. It was ascertained that the chips did not break sufficiently in despite of the long duration milling mechanisms by ball mill. Cryogenic mill provides the energy required for milling mechanisms to act. Disc mill has the highest impact energy was determined. Consequently, efficiency of ball mill is lower than the efficiency of cryogenic and disc type mills. Shape factors of powders produced with ball and cryogenic mills were found greater than that of the powder produced by disc mill. Disc mill has the most efficient and effective impact energy which produces the smaller particles per minute, was determined.
\end{abstract}

Keywords: Direct recycling method, powder production, scrap chips, aluminium alloy.

\section{INTRODUCTION}

Plenty of machine parts are produced by powder metallurgy (P/M) in several industries [1]. Ferrous alloys such as steel and aluminium alloys are the most preferred materials for P/M products like gears, filters, self lubricating bearings and metal powders [1,2]. Aluminium and its alloys are used widely due to its high specific strength, specific electrical conductivity and corrosion resistance [3]. Recycling of aluminium with liquid casting method affects mechanical properties negatively because aluminium has a great affinity with oxygen [4]. Mechanical milling provides better mechanical properties by maintaining the material in solid state [5]. During the mechanical milling powder, impact, abrasive milling, shearing and pressure mechanisms occur simultaneously [6].

The chips formed in the machining process are described as "scrap". This scrap was still contaminated by oil and coolant which contains moisture. To remove this contamination some of chemical methods which are too expensive may be used. For this reason, thermal cleaning methods could be used to remove oil and coolant emulsion [7-9]. Metal chips are compressed as conventional, melted in an electric arc furnace and recycled by casting. By casting the amount of the material reduces. As a result efficiency decreases [10]. Loss of material occurs for many reasons during liquid recycling method [9]. During melting recycling method, some of the metal is lost by burning or as slag [11-13]. If induction furnaces used in the melting process, losses in materials reaches up to $35 \%$. Moreover, because of feeders and shrinkage shares material is lost around $8 \%$ during the casting process. According to this, up to $54 \%$ of the material is recovered in the conventional recycling method [9]. With direct recycling method material losses are reduced to a great extent. With the extracting of $2 \%$ impurities and $3 \%$ extrusion losses, $95 \%$ of the scrap material being recycled by direct recycling method $[10,14]$.

Conventional recycling process is caracterized by high energy consumption, high operating costs and high environmental pollution [15]. Although 6 - 19 GJ/t of consumed energy in melting recycling method, 5 $-6 \mathrm{GJ} / \mathrm{t}$ is enough in direct recycling method $[10,14]$. Due to the decrease in energy requirements, damage to the environment of direct recycling methods is negligible [14- 16]. In terms of efficiency and sustainability in 
industrial production, reduction of environmental pollution is very significant. Moreover, by remelting recycling method labor costs are higher than direct recycling method [14]. Therefore, the economic gains of labor achieved with these new methods increase the competitiveness of enterprises.

In this study, 6013 aluminum alloy of chips was powdered by direct recycling method. The effect of three different types as cryogenic, disc and ball mill was investigated. In order to determine the formation of the aluminium oxide on AA6013 alloy powder optical microscope images were taken and XRD analysis was performed.

\section{MATERIAL AND METHODS}

The chemical composition of AA6013 - T6 aluminium alloy, which is used in present study was given in Table 1. The chips were extracted under commercial coolant by CNC milling from $10 \mathrm{~mm}$ thick plate with 2 $\mathrm{mm}$ depth of cut. The size range of the chips were measured between $4-10 \mathrm{~mm}$, as shown in Figure 1.

Table 1: Chemical composition of AA6013.

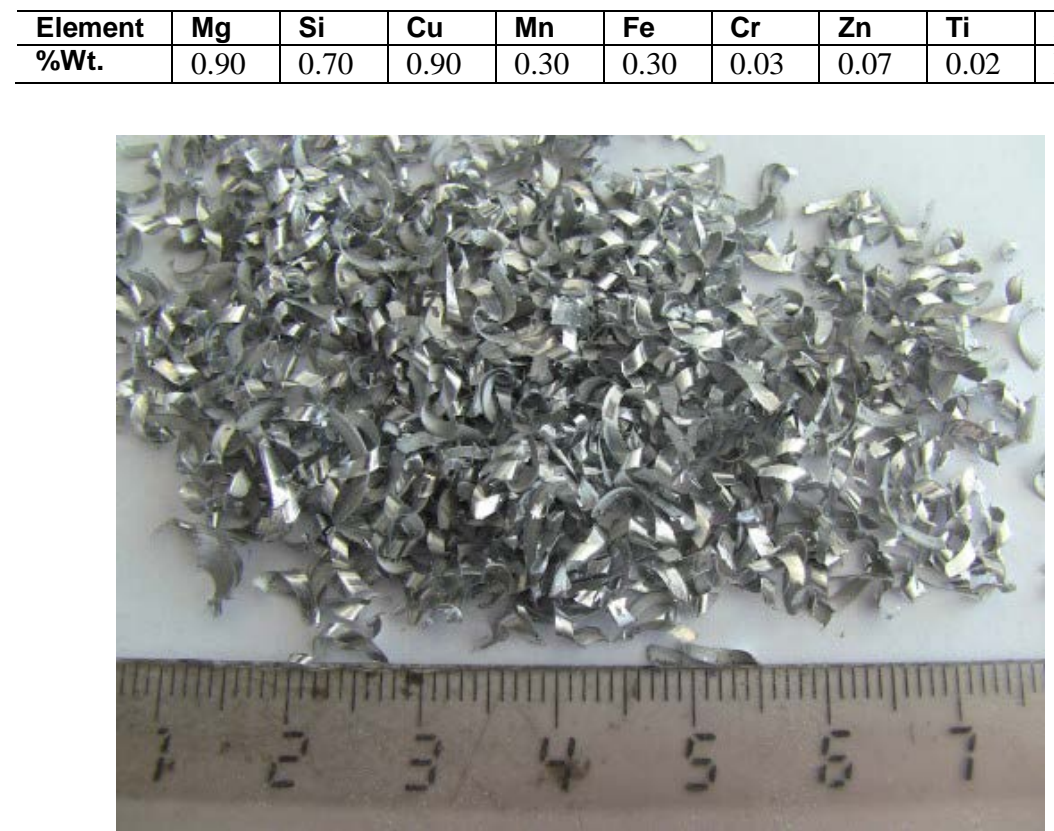

Figure 1: Chips of AA6013 alloy produced by CNC milling.

Part of the chips were milled with Retsch cryogenic mill. $50 \mathrm{ml}$ stainless steel chamber oscillates back-and-forth in horizontal axis. The chamber contains a stainless steel ball, which is $25 \mathrm{~mm}$ in diameter. 3 $\mathrm{g}$ of chips were added to chamber at once and milled for 4 minutes. Total milling process was accomplished with 6 cycles for 24 minutes. Nitrogen was used as cooling atmosphere.

Another part of chips were milled with Retsch RS 200 disc mill. Mill possesses a disc set with $250 \mathrm{ml}$ chamber made of hardened steel. Milling ensues with the axial movement of discs in vertical axis and centrifugal force in consequence of this movement. $22.8 \mathrm{~g}$ chips were added into the disc chamber and transformed to powder by milling with $1500 \mathrm{rpm}$ for 4 minutes.

Last part of AA6013 chips were formed into the powder with Retsch PM 100 ball mill. $500 \mathrm{ml}$ stainless steel mill chamber rotates in vertical axis. Chamber containes a stainless steel ball $25 \mathrm{~mm}$ in diameter, which moves with the aid of centrifugal forces. Initially, $40 \mathrm{~g}$ chips were grinded with $550 \mathrm{rpm}$ for 5 minutes in order to reduce the volume and after that $20 \mathrm{~g}$ more chips were added into the chamber and kept at milling for 15 minutes. Total milled material amount weight $60 \mathrm{~g}$. Due to the insufficient milling time for powder production, the mill was run for 20 minutes more. With this additional milling process, the total milling time was calculated for 40 minutes.

Particle morphology of AA6013 powder was investigated with optical microscope and particle size measurement was achieved by Horiba particle size analyzer using laser diffraction method in ethanol medium. Ultrasonic disaggregation was used before particle size analysis. Also, aspect ratio values of powders have been calculated with 30 particles measured for each mill. XRD analyses of AA6013 powder were carried out in order to determine the possible aluminium oxide formation and other compounds. 


\section{RESULTS AND DISCUSSION}

Present study investigates the effect of mill type on particle size of AA6013 powder produced from chips. Particle sizes for each milled powder were given in Table 2. It was observed that, powders smeared on milling kits in both mills. AA6013 powders milled with disc mill can be seen in Figure 2. Traces of aggregates were observed in powders produced with disc type mill, while the powders of cryogenic grinder exhibited fine dispersion. Smearing powders on disc surface were given in Figure 3. Significant some unmilled chips were observed in powders produced with ball type mill, as shown in Figure 4, therefore the size of these powders cannot be measured by laser diffraction method.

Table 2: Average powder sizes of AA6013.

\begin{tabular}{l|l|l|l}
\hline & Cryogenic Mill & Disc Mill & Ball Mill \\
\hline Average powder size (D50) & $88 \mu \mathrm{m}$ & $42 \mu \mathrm{m}$ & not measured \\
\hline
\end{tabular}

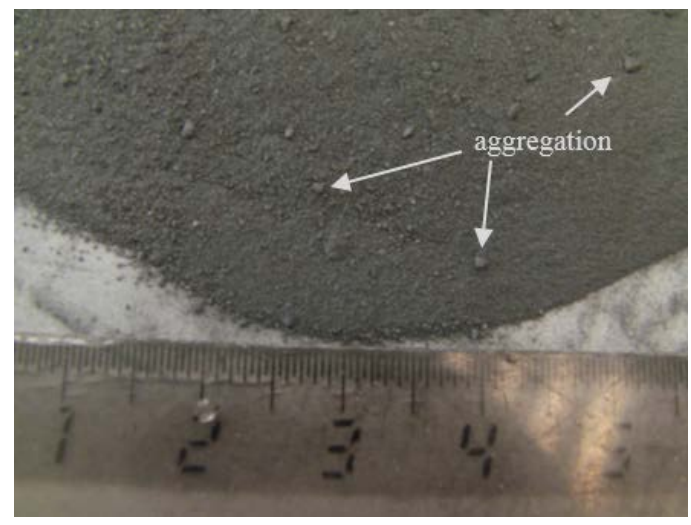

Figure 2: AA6013 powder obtained by disc mill.

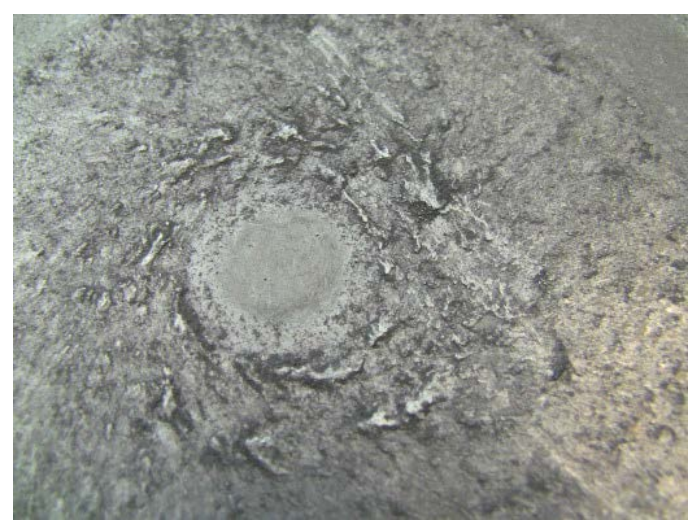

Figure 3: Powders smeared on the disc surface.

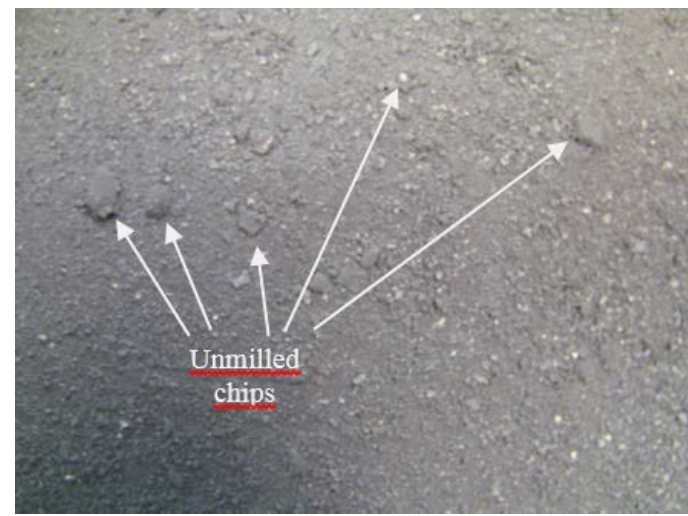

Figure 4: AA6013 powder obtained by ball mill. 
AA6013 powders produced with different mills were investigated under optical microscope. Figure 5 shows the optical microscope images of AA6013 powder produced by cryogenic mill, which resulted flaky and irregular shaped particles. Average aspect ratio of powders produced by cryogenic mill was found 1,42. During the mechanical milling cracks occur initially; fracture and formation of new surfaces ensue cracking [5]. Impact, abrasion, shear and pressure mechanisms occur together in mechanical powder production process. As the size of a particle reduces, stress value for further grinding increases [6]. Cryogenic mill provides the energy required for these mechanisms to act. Crack formation at the side of the particle, which was produced by cryogenic mill is seen in Figure 5b. Particles break into smaller pieces by spreading these cracks. Fracture begins with crack formation; crack spreads for longer grinding times and fracture happens. However, mill reaches asymptotically at least one dimension during operation and working longer does not change the size of powders [6].
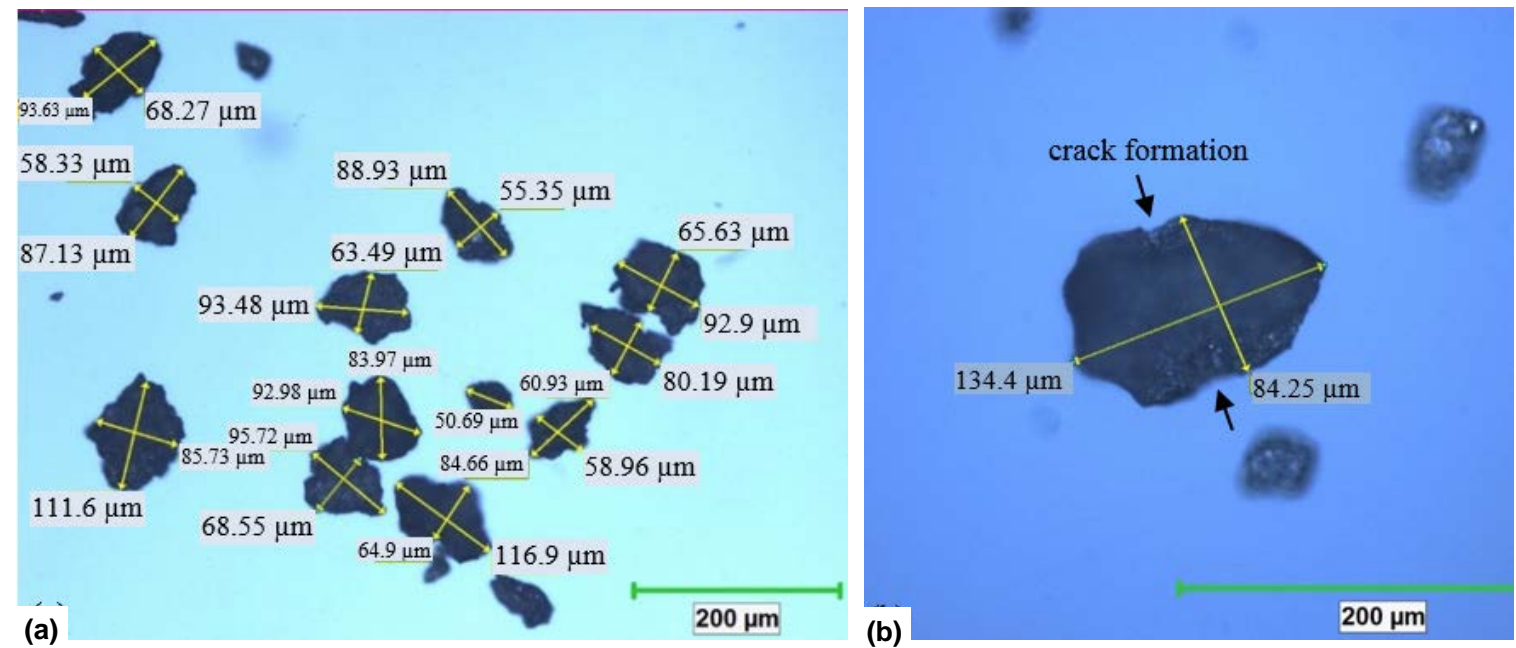

Figure 5: Optical microscope images of AA6013 powder produced by cryogenic mill a)Powders of different sizes b)Crack formation.

Figure 6 shows the optical microscope images of AA6013 powder produced by disc mill. Disc mill resulted flaky and irregular shaped particles. Cracks, which provide new surfaces, were observed at the side of the particle. However formation of these cracks did not result fracture, because required impact energy was not provided. Increasing grinding time might fulfil the impact energy for fracture. However, mill reaches asymptotically at least one dimension during operation and working longer does not change the size of powders [6]. Average aspect ratio of powders produced by disc type grinder was found 1,25. If the aspect ratios of particles produced with cryogenic and disc mill are compared, it can be understood that powder product of disc type mill approaches to equidimensional structure more than that of cryogenic mill.

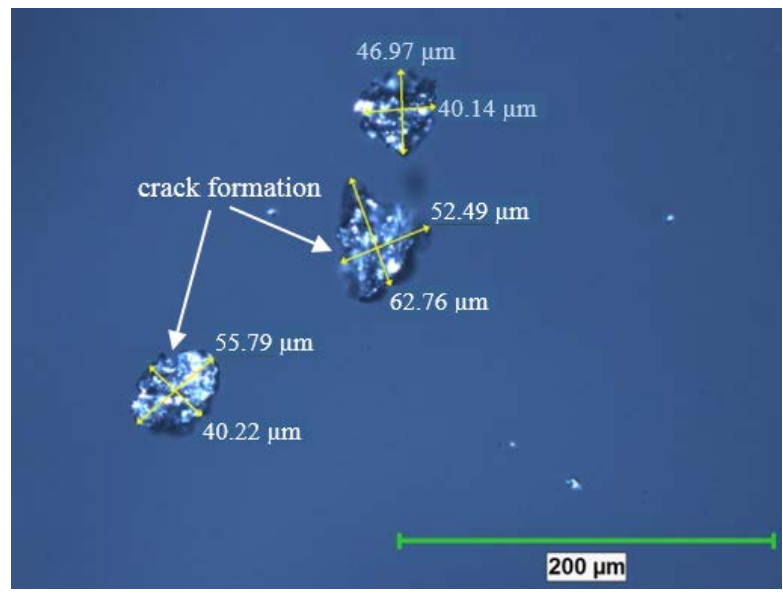

Figure 6: Optical microscope images of AA6013 powder produced by disc mill.

The optical microscope images of AA6013 powder produced by ball mill are shown in Figure 7. As is observed in other mill types, ball mill also result flaky and irregular shaped particles with the average aspect ratio of 1,63. It was ascertained that the chips did not break sufficiently in despite of the long duration milling 
mechanisms. Most of the milling energy is spent by heat and sound in ball mill [6]. For this reason, impact energy provided by ball mill is not enough for breaking coarse particles. Consequently, efficiency of ball mill is lower than the efficiency of cryogenic and disc type mills.

In present study, all particles produced with mechanical milling were found flaky and irregular shaped. In Table 3, the amount of milled material, milling time, particle size and aspect ratio values were given for different mill types. Here, it was determined that, disc mill has the most efficient and effective impact energy which produces the smaller particles per minute.

Ductile materials such as aluminium tends to aggregate in mechanical mill instead of chip off [6]. By increasing milled material amount, aggregation of aluminium powders was observed, which affected the process negatively in ball mill with insufficient impact energy.

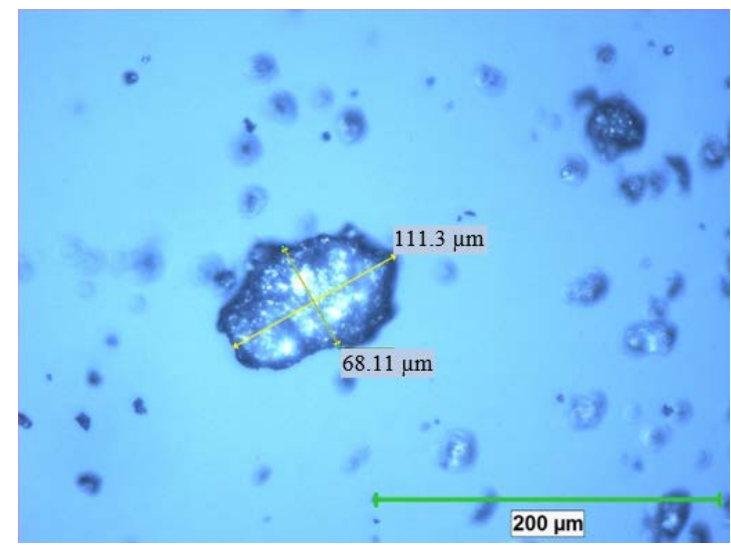

Figure 7: Optical microscope images of AA6013 powder produced by ball mill.

Table 3: Milling parameters and particle size analysis.

\begin{tabular}{l|c|c|c|c}
\hline Mill Type & $\begin{array}{c}\text { Amount of Milled } \\
\text { Material }(\mathbf{g})\end{array}$ & $\begin{array}{c}\text { Milling } \\
\text { Time }(\mathbf{m i n})\end{array}$ & $\begin{array}{c}\text { Particle } \\
\text { Size D50 }(\boldsymbol{\mu m})\end{array}$ & $\begin{array}{c}\text { Aspect Ratio } \\
\text { Values }\end{array}$ \\
\hline Cryogenic & 3 & 24 & 88 & 1.42 \\
\hline Disc & 22.8 & 4 & 42 & 1.25 \\
\hline Ball & 60 & 40 & - & 1.63 \\
\hline
\end{tabular}

XRD graphics of AA6013 powders produced with different mills were given in Figure 8. It was observed that, the powder products of ball and cryogenic mills possess aluminium oxide as the powder product of disc mill was found oxide - free. It was thought that the oxide formation is related to shape factor $\left(\mathrm{K}_{\mathrm{s}}\right)$ and surface area. Volume and surface area of a particle can be calculated assuming the particle shape as ideal sphere:

$$
\begin{aligned}
& A=\pi \cdot D^{2} \\
& V=\frac{\pi \cdot D^{3}}{6}
\end{aligned}
$$
as:

$$
\frac{A}{V}=\frac{6}{D}
$$

Spherical or not, surface area/volume ratio of a particle can be defined as follows:

$$
\frac{A}{V}=\frac{K_{s}}{D} \rightarrow K_{s}=\frac{A \cdot D}{V}
$$



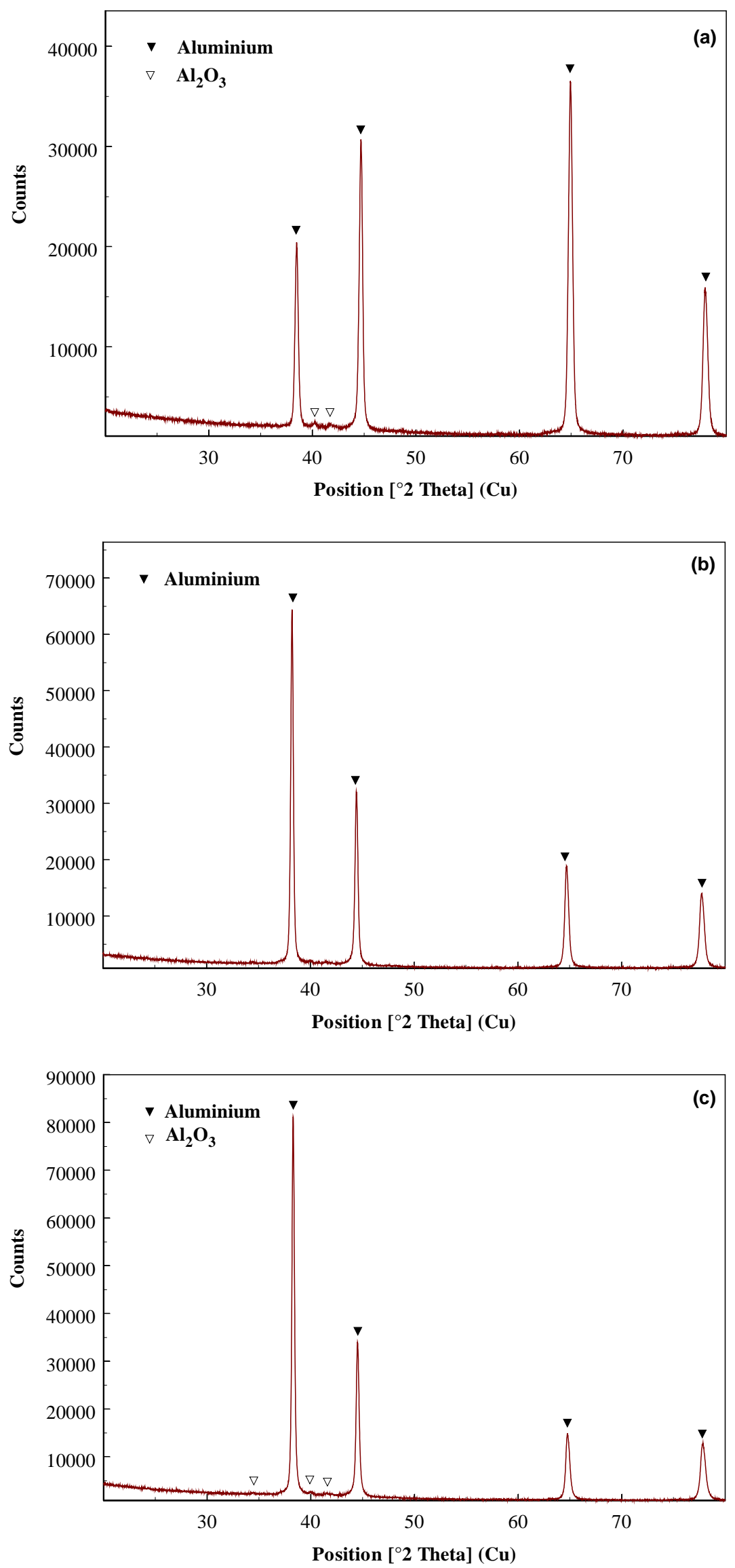

Figure 8: XRD graphics of AA6013 powders produced with different mills a) Cryogenic mill b) Disc mill c) Ball mill

Here, $K_{s}$ is defined as shape factor. Shape factor is assumed $K_{s}=6$ for spherical particles and $K_{s}>6$ for non-spherical particles. For a given total powder weight, surface area increases as the particle size 
decreases and the shape factor increases. Increasing surface area means that more surfaces for formation of oxidation [2]. AA6013 powder produced with disc mill possesses minimum average particle size and aspect ratio. Shape factor of AA6013 powder product of disc mill was found minimum, hence these particles have the minimum surface area and did not exhibit oxide formation, as shown in Figure 8b.

As is seen from Figure 8a and Figure 8c, aluminium oxide was detected in AA6013 powders milled by cryogenic and ball mills. Shape factors of powders produced with ball and cryogenic mills were found greater than that of the powder produced by disc mill. It can be concluded that increasing surface area increased the oxidation tendency of aluminium powder particles.

\section{CONCLUSIONS}

In this study, 6013 aluminum alloy of chips was powdered by direct recycling method. The effect of three different types as cryogenic, disc and ball mill was investigated. In order to determine the formation of the aluminium oxide on AA6013 alloy powder optical microscope images were taken and XRD analysis was performed. According to this:

1. Mechanical milling resulted flaky and irregular shaped AA6013 particles. A trace of aggregates were observed in powders produced with disc mill, while the powders of cryogenic mill exhibited fine dispersion. Significant amount of large aggregates and some unmilled particulates were observed in powders produced with ball type mill

2. Disc mill produce powder from more chips in less time. Accordingly, disc mill was more effective than cryogenic and ball mills. Impact energy provided by ball mill is insufficient to mechanical milling. It was ascertained that the chips did not break sufficiently in despite of the long duration milling mechanisms. Most of the milling energy is spent by heat and sound in ball mill. For this reason, impact energy provided by ball mill is not enough for breaking coarse particles. Cryogenic mill provides the energy required for milling mechanisms to act. Consequently, efficiency of ball mill is lower than the efficiency of cryogenic and disc type mills.

3. Shape factors of powders produced with ball and cryogenic mills were found greater than that of the powder produced by disc mill.

4. Disc mill has the most efficient and effective impact energy which produces the smaller particles per minute, was determined.

\section{ACKNOWLEDGEMENT}

To Scientific Research Project 2013 - 102 supported by University of Manisa Celal Bayar and to Restch Turkey - Kutay Group Co.

\section{BIBLIOGRAPHY}

[1] UYGUR, E.M. "Powder metallurgy in the World and Turkey”, Journal of Applied Research, 1982.

[2] GROOVER, M.P., Principles of modern manufacturing, 4 ed., USA, John Wiley \& Sons Inc., 2010.

[3] SAHIN, Y., Introduction to composite materials, 1 ed., Ankara, Seçkin Press, 2006.

[4] CITAK, R., Production of aluminium matrix composites via oxidation of barium-aluminium metallic powder precursor at low temperature, Ph.D Thesis, University of Gazi Institute of Science and Technology, Ankara, Turkey, 1998.

[5] THUMMLER, F., OBERACKER, R. An introduction to powder metallurgy, 1 ed., USA, Institute of Materials University of Michigan, 1993.

[6] GERMAN, R.M., Powder Metallurgy and Particulate Materials Processing, 1 ed., New Jersey, Metal Powder Industries Federation, 2005.

[7] GRONOSTAJSKİ, J., et al., "Recycling of aluminium chips”, Mechanic , n.819, 1994.

[8] SAMUEL, M., et al., Mechanical properties and industrial application of aluminium base composites, in:Proceedings of the Second International Seminar for Novel Technology of Metal Forming, TEMPUS FEP Program No. 7951, Wroclaw, Poland, 1996.

[9] SAMUEL, M., A new technique for recycling aluminium scrap, Journal of Materials Processing Technology, v. 135, n.1, pp. 117-124, 2007.

[10] MINDIVAN, H., KAYALI, E.S., CIMENOGLU, H., "Recycling of aluminium machining chips”, In: 12th International Materials Symposium IMSP’2008, 109-113, Denizli-TURKEY, 13-17 October 2008. 
[11] LAZZARO, G., VITTORI, S., "Metal and energy saving by direct and continuous extrusion of aluminium scraps”, In: 121st TMS Annual Meeting, San Diego, CA, 1992.

[12] DOMKE, W. Vademecum Materialoznawstwa, 1 ed., Warszawa, PWN, 1989.

[13] MARTYN, P., LALLEMENT, Y., DELAY, J., et al., Aluminium and energy, Ind. Environ., v. 13, pp. 2-43, 1990.

[14] GRONOSTAJSKI, J., MARCINIAK, H., MATUSZAK, A. "New methods of aluminium and aluminium-alloy chips recycling”, Journal of Materials Processing Technology, v. 106, n.1-3, pp. 34-39, 2000.

[15] GRONOSTAJSKI, J.Z., KACZMAR, J.W., MARCINIAK, H., et al., Direct recycling of aluminium chips into extruded products, Journal of Materials Processing Technology, v. 64, n.1-3, pp. 149-156, 1997.

[16] SHARMA, S., NAKAGAWA, T. "Recent development in the recycling of machining swarfs by sintering and powder forging”, Ann. CIRP, v. 25, n. 1, 1977. 